\title{
Identification of prognostic values defined by copy number variation, mRNA and protein expression of $L A N C L 2$ and EGFR in glioblastoma patients
}

\author{
Hua-fu Zhao ${ }^{1 \dagger}$, Xiu-ming Zhou ${ }^{1,2+}$, Jing Wang ${ }^{3,4,5}$, Fan-fan Chen ${ }^{1}$, Chang-peng Wu ${ }^{1,6}$, Peng-yu Diao',

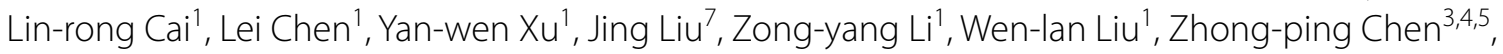 \\ Guo-dong Huang ${ }^{1 *}$ and Wei-ping $\mathrm{Li}^{1^{*}}$
}

\begin{abstract}
Background: Epidermal growth factor receptor (EGFR) and lanthionine synthetase C-like 2 (LanCL2) genes locate in the same amplicon, and co-amplification of EGFR and $L A N C L 2$ is frequent in glioblastoma. However, the prognostic value of $L A N C L 2$ and EGFR co-amplification, and their mRNA and protein expression in glioblastoma remain unclear yet.

Methods: This study analyzed the prognostic values of the copy number variations (CNVs), mRNA and protein expression of LANCL2 and EGFR in 575 glioblastoma patients in TCGA database and 100 glioblastoma patients in tumor banks of the Shenzhen Second People's Hospital and the Sun Yat-sen University Cancer Center.

Results: The amplification of LANCL2 or EGFR, and their co-amplification were frequent in glioblastoma of TCGA database and our tumor banks. A significant correlation was found between the CNVs of LANCL2 and EGFR ( $p<0.001)$. CNVs of LANCL2 or EGFR were significantly correlated with IDH1/2 mutation but not MGMT promoter methylation. Multivariate analysis showed that $L A N C L 2$ amplification was significantly correlated with reduced overall survival (OS) in younger ( $<60$ years) glioblastoma patients of TCGA database $(p=0.043, \mathrm{HR}=1.657)$ and our tumor banks $(p=0.018, H R=2.199)$. However, LANCL2 or EGFR amplification, and their co-amplification had no significant impact on OS in older ( $\geq 60$ years) or IDH1/2-wild-type glioblastoma patients. mRNA and protein overexpression of LANCL2 and EGFR was also frequently found in glioblastoma. The mRNA expression rather than the protein expression of LANCL2 and EGFR was positively correlated $(p<0.001)$. However, mRNA or protein expression of EGFR and LANCL2 was not significantly correlated with OS of glioblastoma patients. The protein expression level of LANCL2, rather than EGFR, was elevated in relapsing glioblastoma, compared with newly diagnosed glioblastoma. In addition, the intracelIular localization of LanCL2, not EGFR, was associated with the grade of gliomas.
\end{abstract}

*Correspondence: huangguodong@email.szu.edu.cn; wpli@szu.edu.cn

${ }^{\dagger}$ Hua-fu Zhao and Xiu-ming Zhou contributed equally to the work

${ }^{1}$ Department of Neurosurgery, Institute of Translational Medicine, The

First Affiliated Hospital of Shenzhen University, Shenzhen Second People's

Hospital, Shenzhen 518035, China

Full list of author information is available at the end of the article

(c) The Author(s) 2021. Open Access This article is licensed under a Creative Commons Attribution 4.0 International License, which permits use, sharing, adaptation, distribution and reproduction in any medium or format, as long as you give appropriate credit to the original author(s) and the source, provide a link to the Creative Commons licence, and indicate if changes were made. The images or other third party material in this article are included in the article's Creative Commons licence, unless indicated otherwise in a credit line to the material. If material is not included in the article's Creative Commons licence and your intended use is not permitted by statutory regulation or exceeds the permitted use, you will need to obtain permission directly from the copyright holder. To view a copy of this licence, visit http://creativecommons.org/licenses/by/4.0/. The Creative Commons Public Domain Dedication waiver (http://creativeco mmons.org/publicdomain/zero/1.0/) applies to the data made available in this article, unless otherwise stated in a credit line to the data. 
Conclusions: Taken together, amplification and mRNA overexpression of LANCL2 and EGFR, and their co-amplification and co-expression were frequent in glioblastoma patients. Our findings suggest that amplification of LANCL2 and EGFR were the independent diagnostic biomarkers for glioblastoma patients, and LANCL2 amplification was a significant prognostic factor for OS in younger glioblastoma patients.

Keywords: Glioblastoma, LANCL2, EGFR, Overall survival, Amplification, Overexpression

\section{Background}

Glioblastoma multiforme (glioblastoma, GBM), belonging to the highest World Health Organization (WHO) grade glioma (grade IV), is the most common malignant and aggressive primary brain tumor (47.7\%) with a high mortality rate $[1,2]$. According to the 2018 CBTRUS report, the incidence rate of GBM is 3.21 per 100,000 populations, which is the highest in malignant brain tumors [2, 3]. Under the Stupp's therapeutic protocol (maximal surgical resection followed by adjuvant radiotherapy and chemotherapy with temozolomide), the median overall survival of GBM patients is 14.6 months, while the 2-year overall survival (OS) rate and progression-free survival (PFS) rate is $26.5 \%$ and $10.7 \%$, respectively [4]. Aberrations of molecular markers such as $\mathrm{O}(6)$-methylguanine-DNA methyltransferase (MGMT) promoter methylation, codeletion of $1 \mathrm{p}$ and $19 \mathrm{q}$, isocitrate dehydrogenase 1 and 2 (IDH1 and IDH2) mutation, telomerase reverse transcriptase (TERT) promoter mutation, TP53 mutation, and epidermal growth factor receptor (EGFR) overexpression show prognostic significance to guide treatment decisions of GBM patients. In particular, $I D H 1 / 2$ gene mutations are found in more than $70 \%$ of grade II-III glioma and secondary GBM that arises from low-grade glioma. GBM patients with $I D H 1 / 2$ gene mutations often have a better clinical outcome than those with wild-type $I D H$ [5]. TERT promoter mutation is found in approximately $80 \%$ of patients with primary GBM that develops rapidly without any clinical or histologic evidence of a less malignant precursor lesion. GBM patients with TERT promoter mutation often have poor survival and a high risk of death [6].

EGFR, a member of receptor tyrosine kinases (RTKs), is essential to the pathological process in various cancers via activation of PI3K/Akt signaling pathway. Analyzed by The Cancer Genome Atlas (TCGA) database, overall alterations including amplification, mutation, rearrangement and altered splicing of EGFR gene in GBM are highly frequent (57.4\%) [7]. Compared with secondary GBM, EGFR amplification (36\%) and overexpression (more than 60\%) are more common in primary GBM [8, 9]. Evidence shows that EGFR gene amplification has a strong correlation with EGFR overexpression. Approximate $98 \%$ of primary GBM with EGFR amplification also exhibit EGFR overexpression, while $70 \%-90 \%$ of those with EGFR overexpression show EGFR amplification [8, 10]. A number of studies demonstrate that the amplification and overexpression of EGFR are associated with poor prognosis of GBM patients, especially young people [10-12]. However, a retrospective study shows that EGFR amplification is not a prognostic factor for GBM patients treated with surgery. And a meta-analysis also shows that $E G F R$ amplification is not significantly associated with OS of GBM patients, indicating a heterogeneity of significance among difference studies and subjects [13].

Lanthionine synthetase C-like 2 (LanC Like 2, LanCL2), a member of eukaryotic LanC-like protein family, is a homologue of prokaryotic LanC involved in the synthesis of the antibiotic named as lantibiotics [14]. LanCL2 is a receptor of abscisic acid (ABA) which is not only a plant hormone but also an endogenous mammalian hormone involved in glycemic control [15]. It is also known as testis adriamycin sensitivity protein (TASP) that is able to increase sensitivity of tumor cells to adriamycin via reduction of P-glycoprotein [16]. Accumulating evidence show that LanCL2 plays important roles in the regulation of stress response, inflammation and glycometabolism, providing a potential target for the treatment of chronic inflammatory, metabolic and immune-related diseases $[17,18]$. LANCL2, along with SEC61G and ECOP genes, are located in the flank of $E G F R$ gene at chromosomal $7 \mathrm{p} 11.2$. These genes are in the same amplicon, and their co-amplification with EGFR is common in GBM patients $[19,20]$. However, it is not clear that whether co-amplification of EGFR and LANCL2 has prognostic value for GBM patients, and what are their mRNA and protein expression patterns.

Here, this study analyzed the copy number variations (CNVs), mRNA and protein expression profiles, and their prognostic values of $L A N C L 2$ and EGFR in GBM specimens from TCGA database or from the tumor banks of Shenzhen Second People's Hospital and Sun Yat-sen University Cancer Center. We showed that amplification and mRNA overexpression of LANCL2 and EGFR, and their co-amplification and co-expression were frequent in GBM patients. Amplification of LANCL2 and $E G F R$ were the independent diagnostic biomarkers for GBM patients, and LANCL2 amplification was a significant prognostic factor for OS in younger GBM patients. The protein expression pattern and role of LanCL2 were 
independent to EGFR. LanCL2 overexpression was correlated with glioblastoma recurrence, and its activation may trigger its translocation into the nucleus.

\section{Methods}

\section{TCGA database analysis}

CNVs and mRNA expression data analyzed using the GISTIC2 algorithm in the TCGA database were achieved in the cBio Cancer Genomics Portal (http://www.cbiop ortal.org) [21, 22]. The TCGA Pan-Cancer Atlas dataset involving more than 11,000 human tumors across 33 different cancer types was selected [23-26]. The clinical data of GBM from the TCGA Pan-Cancer database were downloaded to analyze the OS and PFS of the cohort using Kaplan-Meier survival analysis and log-rank test. Chi-square test was carried out to estimate the correlation of CNVs, while the correlation of mRNA expression (RNASeq V2 RSEM) were calculated by Pearson's correlation. CNVs including shallow deletion (possibly heterozygous deletion), diploid, low-level gain and high-level amplification were defined as the putative copy number values of $-1,0,1$ and 2 , respectively.

\section{Tumor specimens}

Tumor specimens were retrospectively obtained from the tumor banks in the Shenzhen Second People's Hospital and the Sun Yat-sen University Cancer Center. All tumor samples were histologically diagnosed as GBM (WHO grade IV). Four human normal brain tissues (including two craniocerebral trauma, one para-carcinoma and one epilepsy) and four grade I gliomas were used as the negative controls. Identification of all tumor samples or normal brain tissues were confirmed by an experienced pathologist. This study was approved by the Research Ethics Committee of Shenzhen Second People's Hospital and Sun Yat-sen University Cancer Center. All patients were given written informed consent.

\section{DNA extraction and copy number assay}

Genomic DNA (gDNA) was extracted using QIAamp DNA Mini Kit (QIAGEN) and copy number variations were evaluated by TaqMan Copy Number Assays (Thermo Scientific) following the manufacturer's instructions. The Taqman Copy Number Assay probes for LANCL2 (Hs04953915_cn) and EGFR (Hs04983302_cn) genes were used for copy number quantitation, while TaqMan Copy Number Reference Assay RNase P was served as the reference. TaqMan Genotyping Master Mix was employed for the PCR amplification procedure, and $20 \mathrm{ng} /$ well of gDNA was added in each PCR reaction, which was performed in ABI Quantstudio ${ }^{\mathrm{TM}}$ DX. Each reaction was duplicated.

\section{Western blotting}

Total proteins were extracted by RIPA lysis buffer and protein concentrations were determined using the $\mathrm{BCA}$ protein assay (Thermo Scientific). Proteins were then separated by $8 \%$ SDS-PAGE and transferred to PVDF membranes (Millipore). After blocking with 5\% non-fat milk or $5 \% \mathrm{BSA}$, membranes were incubated with gentle agitation in primary antibodies $(1: 1000)$ overnight at $4{ }^{\circ} \mathrm{C}$ and then in HRP-conjugated secondary antibodies (1:5000) for $1 \mathrm{~h}$ at room temperature. Positive signals were visualized by ECL chemiluminescence using ChemiDoc MP Imaging System (Bio-Rad).

\section{Immunohistochemistry (IHC)}

Tissue microarray slides containing 60 to 80 of paraffin-embedded glioma tissue specimens (Cat.No: HBraGli060PG-01 and HBra-G080PG-01) were purchased from Shanghai Outdo Biotech Company. Slide HBraGli060PG-01 included 3 normal brain tissues (1 white matter and 2 cortex), 3 grade I, 9 grade II, 9 grade III, and 34 grade IV gliomas (GBM). Slide HBra-G080PG-01 included 3 normal brain tissues (1 white matter and 2 cortex), 3 grade I, 8 grade II, 22 grade III, and 44 grade IV gliomas (GBM), which shared 54 samples with HBra-Gli060PG-01. The use of human tissues in tissue microarray slides was approved by the Ethics Committee of Shanghai Outdo Biotech Company. Sections were immunostained with appropriate primary antibody and biotin-conjugated goat anti-rabbit IgG. After the detection using DAB detection kit (Boster), slides were counterstained with hematoxylin, dehydrated and mounted. IHC staining scores were calculated as the product of the proportion of positive staining cells $(0-4)$ and the intensity of staining $(0-3)$. The proportion of positive staining cells was graded as followed: 0 (no staining); 1 (1\%-25\%, including 25\%); 2 (25\%-50\%, including $50 \%)$; $3(50 \%-$ $75 \%$, including $75 \%) ; 4(>75 \%)$. The intensity of staining was graded as followed: negative $=0$; weakly positive $=1$; positive $=2$; strongly positive $=3$.

\section{Statistical analysis}

Data were presented as mean \pm S.E.M and all statistical analyses were carried out using GraphPad Prism 8 and SPSS Statistic 22.0 software. Relative protein expression was evaluated by measurement of density of Western blotting bands using Image J software. Difference among groups which did not follow a normal distribution was compared using the Mann-Whitney $U$ test or Kruskal-Wallis One-way ANOVA with Dunn's multiple comparisons test. Patients' survival analyzed using the Kaplan-Meier method and the log-rank test was used for univariate analysis. Multivariate analysis of OS was 
performed using the Cox proportional hazards regression model in a forward stepwise manner. The distribution of categorical values within two groups was analyzed by the chi-square test (Fisher's exact test). The difference was considered to be significant at $p<0.05$. The licenses of software are available under any requirement for permission for use.

\section{Results}

\section{Amplification and co-amplification of LANCL2 and EGFR were prevalent in glioblastoma, and LANCL2 amplification was an independent prognostic factor for younger glioblastoma patients}

Firstly, to investigate the CNVs of LANCL2 and EGFR genes in a panel of cancers, 32 studies of different cancer types in TCGA Pan-Cancer Atlas database $(n=10,967)$ were selected. Results showed that the dominant genomic alterations of LANCL2 and EGFR in cancers were amplification and mutation, while gene fusion and deep deletion were rare. Glioblastoma, head and neck squamous cell carcinoma, esophagogastric adenocarcinoma and non-small cell lung cancer were the top four tumors with the highest alteration frequencies of LANCL2 and EGFR (Fig. 1A, B). Subsequently, two studies Glioblastoma Multiforme $(\mathrm{n}=592)$ and Brain Lower Grade Glioma $(\mathrm{n}=514)$ were further analyzed. The amplification frequencies of LANCL2 and EGFR in GBM were up to $27.65 \%$ (159 of 575 cases) and $44.35 \%$ (255 of 575 cases), whereas those in low-grade glioma (LGG) were only $3.91 \%$ (20 of 511 cases) and 7.63\% (39 of 511 cases), respectively (Fig. 1C). The data of LGG contained grade II and III gliomas, including oligodendroglioma, oligoastrocytoma and astrocytoma. Among the LGG data, the amplification frequencies of LANCL2 and EGFR in astrocytoma were the highest $(7.33 \%$ and $13.92 \%$, respectively), while those in oligoastrocytoma were the lowest (1.07\% and 1.60\%, respectively) (Fig. 1D). Co-amplification of LANCL2 and EGFR was common in GBM, but it was rare in LGG. LANCL2 amplification was found in $61.96 \%$ of GBM samples and $51.28 \%$ of LGG samples containing EGFR amplification. Furthermore, nearly all GBM and LGG samples containing LANCL2 amplification displayed EGFR amplification (Fig. 1E). The main types of LANCL2 and EGFR CNVs in GBM were copy number gain and amplification, whereas shallow deletion and diploid were infrequent. Chi-square test demonstrated a significant correlation between the CNVs of LANCL2 and EGFR ( $p<0.001)$ (Fig. 1F). We analyzed the top ten genes which had the highest co-amplification frequencies with $L A N C L 2$ or EGFR. Results indicated that the amplification frequencies of EGFR, SEC61G and $V O P P 1$ genes were the top three highest in LANCL2amplified GBM samples, while SEC61G, LANCL2 and
VSTM2A were the top three genes co-amplified with EGFR (Fig. 1G). The relationship between CNVs of LANCL2/EGFR and molecular pathology of GBM samples was analyzed. Wild-type $I D H 1 / 2$ was mainly found in GBM samples with LANCL2/EGFR gain or amplification. Chi-square test found that CNVs of LANCL2 or $E G F R$ were significantly correlated with $I D H 1 / 2$ mutation but not MGMT methylation status (Fig. 1H, Additional file 1: Figure S1A, B).

Univariate analysis was performed to evaluate the difference of OS and PFS for the variables (age, gender, ethnicity, LANCL2 and EGFR genes status). Results showed that old age ( $\geq 60 \mathrm{yrs}$ ), gender (male), LANCL2 or EGFR amplification and their co-amplification were the significant factors contributing to shorter OS, whereas age was the only variable markedly associated with PFS (Table 1 ). Hazard ratios (HR) of these variables were demonstrated in the forest plot (Fig. 1I). Kaplan-Meier survival curves were also drawn in Additional file 1: Figure S1C. Ethnicity did not have a significant impact on OS, which may be due to the lack of the number of Hispanic or Latino $(n=5)$. Thus, ethnicity was excluded as a covariate in the subsequent multivariate analysis. Since only $284 \mathrm{GBM}$ patients have all the data of age, gender, LANCL2 and $E G F R$ genes status, we performed multivariate analysis for OS on theses 284 patients of TCGA database. Results showed that age $(p<0.001, H R=2.221)$ and gender $(p=0.029, \mathrm{HR}=1.382)$ were the independent prognostic factors for OS. The prognostic values of LANCL2 or EGFR amplification and their co-amplification were not sufficient to reach significance (Table 2). Further, according to the age at diagnosis, GBM patients were divided into two categories: younger $(<60$ yrs $)$ and older $(\geq 60$ yrs) patients. Univariate analysis found that only gender $(p=0.002, \mathrm{HR}=1.894)$ were significantly correlated with OS of younger GBM patients. LANCL2 amplification and LANCL2 \& EGFR co-amplification displayed the same results of univariate analysis, since all the patients with LANCL2 amplification had LANCL2 \& EGFR coamplification (Fig. 1J, Table 3). Surprisingly, multivariate analysis showed that gender $(p=0.002, \mathrm{HR}=2.029)$ and LANCL2 amplification $(p=0.043, \mathrm{HR}=1.657)$ were independent significant prognostic factors for OS in younger GBM patients (Table 4). However, these variables (including gender, $L A N C L 2$ and EGFR genes status) had no significant impact on OS in older ( $\geq 60$ yrs) GBM patients (Additional file 1: Table S1). Due to the strong association between $L A N C L 2 / E G F R$ amplification and wild-type $I D H 1 / 2$, univariate and multivariate analyses for survival was performed to investigate the prognostic values of LANCL2 and EGFR amplification in IDH1/2-wild-type GBM patients. Results found that only age and gender had a significant impact on OS of $I D H 1 / 2$-wild-type GBM 

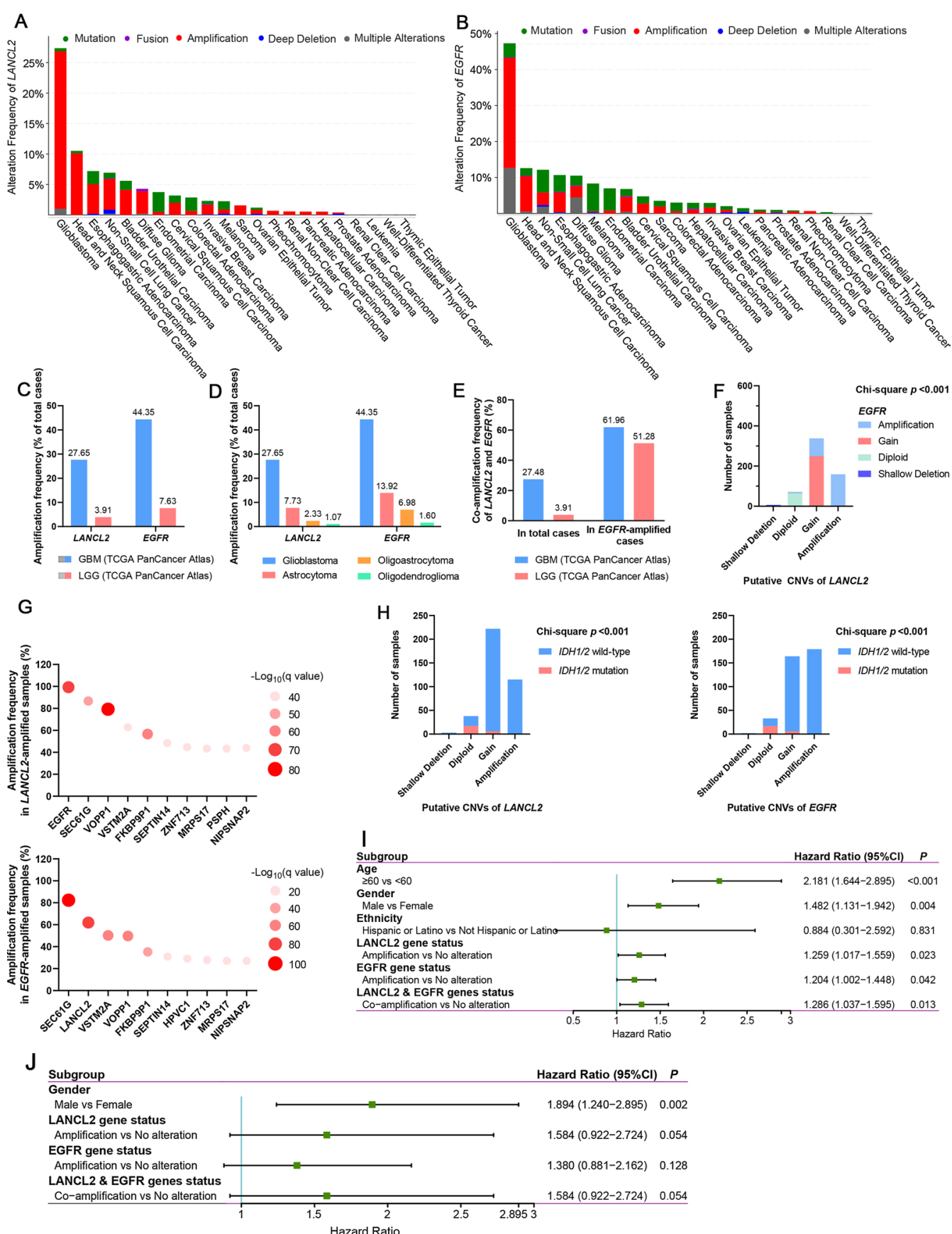

Fig. 1 Amplification and co-amplification of LANCL2 and EGFR were frequent in GBM specimens of TCGA database, and LANCL2 amplification were associated with poor OS in younger GBM patients. A, B Genetic alteration frequencies of LANCL2 and EGFR in 32 different cancers of TCGA Pan-Cancer Atlas database. The diagrams showed the top 22 cancers with the highest frequencies. C Amplification frequencies of $L A N C L 2$ and EGFR in two TCGA studies of Glioblastoma Multiforme $(n=592)$ and Brain Lower Grade Glioma $(n=514)$. D Amplification frequencies of LANCL2 and EGFR in different pathological types of gliomas. $\mathbf{E}$ Co-amplification frequencies of $L A N C L 2$ and EGFR in total or EGFR-amplified GBM samples. $\mathbf{F}$ Chi-square test (Fisher's exact test) showed the CNVs of LANCL2 and EGFR in GBM were significantly associated. G The top 10 genes with the highest amplification frequencies in LANCL2- or EGFR-amplified GBM samples. $\mathbf{H}$ Chi-square test showed that CNVs of LANCL2 and EGFR were significantly correlated with IDH1/2 mutation status in GBM. I Forest plot showing the univariate analysis for OS in GBM patients of TCGA database. J Forest plot showing the univariate analysis for OS in younger ( $<60$ years) GBM patients of TCGA database. $P$ values and hazard ratios were determined by log-rank test 
Table 1 Univariate analysis for OS and PFS in GBM patients of TCGA database

\begin{tabular}{|c|c|c|c|c|c|}
\hline Variable & No. (\%) & Median OS (months) & $P$ & Median PFS (months) & $P$ \\
\hline Age (years) & & & $<0.001$ & & 0.007 \\
\hline$\geq 60$ & $152(52.96)$ & 11.28 & & 5.82 & \\
\hline$<60$ & $135(47.04)$ & 17.79 & & 7.86 & \\
\hline Gender & & & 0.009 & & 0.145 \\
\hline Male & $169(58.89)$ & 13.35 & & 7.04 & \\
\hline Female & $118(41.11)$ & 15.65 & & 7.36 & \\
\hline Ethnicity & & & 0.954 & & 0.686 \\
\hline Hispanic or Latino & $5(2.21)$ & 14.22 & & 5.98 & \\
\hline Not Hispanic or Latino & $221(97.79)$ & 14.01 & & 7.04 & \\
\hline LANCL2 gene status & & & 0.023 & & 0.123 \\
\hline Amplification & $157(27.12)$ & 13.78 & & 6.67 & \\
\hline No alteration & $422(72.88)$ & 14.50 & & 7.20 & \\
\hline EGFR gene status & & & 0.042 & & 0.230 \\
\hline Amplification & $252(43.52)$ & 14.01 & & 6.84 & \\
\hline No alteration & $327(56.48)$ & 14.50 & & 7.66 & \\
\hline LANCL2 and EGFR genes status & & & 0.013 & & 0.509 \\
\hline Co-amplification & $156(26.94)$ & 13.78 & & 6.67 & \\
\hline No alteration & $423(73.06)$ & 14.53 & & 7.30 & \\
\hline LANCL2 mRNA status & & & 0.224 & & 0.664 \\
\hline Overexpression & $56(36.36)$ & 13.78 & & 7.04 & \\
\hline No alteration & $98(63.64)$ & 13.61 & & 5.98 & \\
\hline EGFR mRNA status & & & 0.778 & & 0.136 \\
\hline Overexpression & $75(48.70)$ & 14.93 & & 6.41 & \\
\hline No alteration & $79(51.30)$ & 12.95 & & 6.90 & \\
\hline LANCL2 and EGFR mRNA status & & & 0.930 & & 0.689 \\
\hline Concurrent overexpression & $42(27.27)$ & 15.39 & & 6.41 & \\
\hline No alteration & $112(72.73)$ & 13.12 & & 6.84 & \\
\hline
\end{tabular}

Table 2 Multivariate analysis by the Cox proportional hazard regression model for OS in GBM patients of TCGA database

\begin{tabular}{lll}
\hline Variable & HR $(\mathbf{9 5 \%} \mathbf{C l})$ & $P$ \\
\hline $\begin{array}{l}\text { Age (years) } \\
\geq 60 \text { vs }<60\end{array}$ & $2.221(1.667-2.961)$ & $<0.001$ \\
$\begin{array}{l}\text { Gender } \\
\quad \text { Male vs female }\end{array}$ & $1.382(1.034-1.848)$ & 0.029 \\
$\begin{array}{l}\text { LANCL2 gene status } \\
\quad \text { Amplification vs no alteration }\end{array}$ & NA & 0.351 \\
$\begin{array}{l}\text { EGFR gene status } \\
\text { Amplification vs no alteration }\end{array}$ & NA & 0.799 \\
$\begin{array}{l}\text { LANCL2 and EGFR genes status } \\
\text { Co-amplification vs no alteration }\end{array}$ & NA & 0.553 \\
\hline
\end{tabular}

$H R$ hazard ratio, $\mathrm{Cl}$ confidence interval, $N A$ not applicable

patients, whereas $L A N C L 2$ or EGFR amplification and their co-amplification were not significantly correlated with OS and PFS of IDH1/2-wild-type GBM patients (Additional file 1: Figure S1D, Tables S2, S3).
mRNA overexpression of $L A N C L 2$ and EGFR were frequent in glioblastoma, but were not associated with the prognosis of glioblastoma patients

The mRNA expression profiles of LANCL2 and EGFR were investigated in 32 different cancers of TCGA database. In the histograms, the average mRNA expression of LANCL2 and EGFR was organized from lowest to highest priority. Among them, LGG, testicular germ cell carcinoma, GBM and uveal melanoma were the top four tumors with the highest average mRNA expression of LANCL2, while the average mRNA expression of EGFR was highest in GBM, head and neck cancer, clear cell renal cell carcinoma (ccRCC) and LGG (Fig. 2A, B). mRNA overexpression of LANCL2 and EGFR was found in $35.63 \%$ (57 of 160 cases) and $48.13 \%$ (77 of 160 cases) of GBM samples, respectively (Fig. 2C). However, the mRNA overexpression frequencies of LANCL2 and EGFR in LGG samples were only around $10 \%$, and little difference was shown in astrocytoma, oligoastrocytoma and oligodendroglioma (Fig. 2D). The correlation between mRNA expression and CNV of LANCL2 and EGFR was 
Table 3 Univariate analysis for OS in younger GBM patients (age <60 yrs) of TCGA database

\begin{tabular}{|c|c|c|c|c|c|}
\hline Variable & No.(\%) & Median OS (months) & $P$ & Median PFS (months) & $P$ \\
\hline Gender & & & 0.002 & & 0.131 \\
\hline Male & $78(57.78)$ & 15.39 & & 7.86 & \\
\hline Female & $57(42.22)$ & 22.49 & & 8.48 & \\
\hline LANCL2 gene status & & & 0.054 & & 0.177 \\
\hline Amplification & $33(24.44)$ & 15.02 & & 5.85 & \\
\hline No alteration & $102(75.56)$ & 18.08 & & 8.48 & \\
\hline EGFR gene status & & & 0.128 & & 0.795 \\
\hline Amplification & $56(41.48)$ & 17.49 & & 8.12 & \\
\hline No alteration & $79(58.52)$ & 17.79 & & 7.63 & \\
\hline LANCL2 and EGFR genes status & & & 0.054 & & 0.177 \\
\hline Co-amplification & $33(24.44)$ & 15.02 & & 5.85 & \\
\hline No alteration & $102(75.56)$ & 18.08 & & 8.48 & \\
\hline
\end{tabular}

Table 4 Multivariate analysis by the Cox proportional hazard regression model for OS in younger GBM patients (age $<60$ yrs) of TCGA database

\begin{tabular}{lll}
\hline Variable & HR $(\mathbf{9 5 \%} \mathbf{C l})$ & $P$ \\
\hline Gender & $2.029(1.286-3.201)$ & 0.002 \\
$\quad \begin{array}{l}\text { Male vs female } \\
\text { LANCL2 gene status }\end{array}$ & \\
$\quad \begin{array}{l}\text { Amplification vs no alteration } \\
\text { EGFR gene status }\end{array}$ & $1.657(1.017-2.699)$ & 0.043 \\
$\begin{array}{l}\text { Amplification vs no alteration } \\
\text { LANCL2 and EGFR gene status }\end{array}$ & NA & 0.624 \\
$\begin{array}{l}\text { Co-amplification vs no alteration } \\
\text { HR hazard ratio, Cl confidence interval, NA not applicable }\end{array}$ & NA
\end{tabular}

$H R$ hazard ratio, $\mathrm{Cl}$ confidence interval, $N A$ not applicable

then analyzed. Results showed that mRNA expression of LANCL2 was significantly elevated in GBM samples with $L A N C L 2$ amplification, compared with GBM samples with diploid or gain of LANCL2 (Fig. 2E). Likewise, the correlation was the same in EGFR (Fig. 2F). Concurrent mRNA overexpression of LANCL2 and EGFR was found in $26.25 \%$ (42 of 160 cases) of total GBM samples and $54.55 \%$ ( 42 of 77 cases) of EGFR-overexpressed GBM samples (Fig. 2G). In addition, linear regression analysis demonstrated that mRNA expression of LANCL2 and EGFR was positively correlated $(p<0.001)$ (Fig. $2 \mathrm{H})$. To investigate the prognostic values of LANCL2 or EGFR mRNA expression, Kaplan-Meier survival and univariate analyses were performed. We showed that mRNA overexpression of LANCL2 or EGFR, and their concurrent overexpression were not significantly associated with OS and PFS of GBM patients (Table 1, Fig. 2I, Additional file 1: Figure S2A). Interestingly, mRNA expression levels of EGFR were significantly elevated in $I D H 1 / 2$-wildtype GBM samples, while no obvious change of $L A N C L 2$
mRNA expression was found, suggesting a significant association between EGFR mRNA expression and $I D H 1 / 2$ status (Additional file 1: Figure S2B). However, mRNA overexpression of $L A N C L 2$ or EGFR was also not significantly associated with OS and PFS of $I D H 1 / 2$-wildtype GBM patients (Additional file 1: Figure S2C).

\section{Amplification and co-amplification LANCL2 and EGFR were also frequent in glioblastoma from the tumor banks, and $L A N C L 2$ amplification was associated with poor overall survival of glioblastoma patients}

To validate the analysis results of TCGA database, we analyzed the copy numbers of 100 GBM patients' samples from our tumor banks by Taqman Copy Number Assay using fluorescent probes targeting LANCL2 and $E G F R$. The $\log _{2}$ copy number value larger than 2 was regarded as amplification. Results showed that compared with the copy numbers in normal brain tissues and grade I gliomas, the copy numbers of $E G F R$ were significantly elevated in GBM, while the copy numbers of LANCL2 had no obvious changes (Fig. 3A, B). Interestingly, when the GBM samples were subdivided into newly diagnosed and relapsing tumors, the copy numbers of $L A N C L 2$ and $E G F R$ were significantly increased only in newly diagnosed GBM (Fig. 3E, F). The amplification frequencies of LANCL2 and EGFR were $62.00 \%$ and $55.00 \%$ in $100 \mathrm{GBM}$ patients, respectively (Fig. $3 \mathrm{C}$, Table 4). LANCL2 and EGFR co-amplification was found in $47.00 \%$ of the total GBM samples and $85.45 \%$ of GBM samples containing EGFR amplification (Fig. 3D, Additional file 1: Table S5). Pearson's correlation analysis also showed that the copy numbers of $L A N C L 2$ and EGFR were positively correlated with each other (Fig. 3G). Kaplan-Meier survival and univariate analyses demonstrated that age, LANCL2 or EGFR amplification, and their co-amplification were 


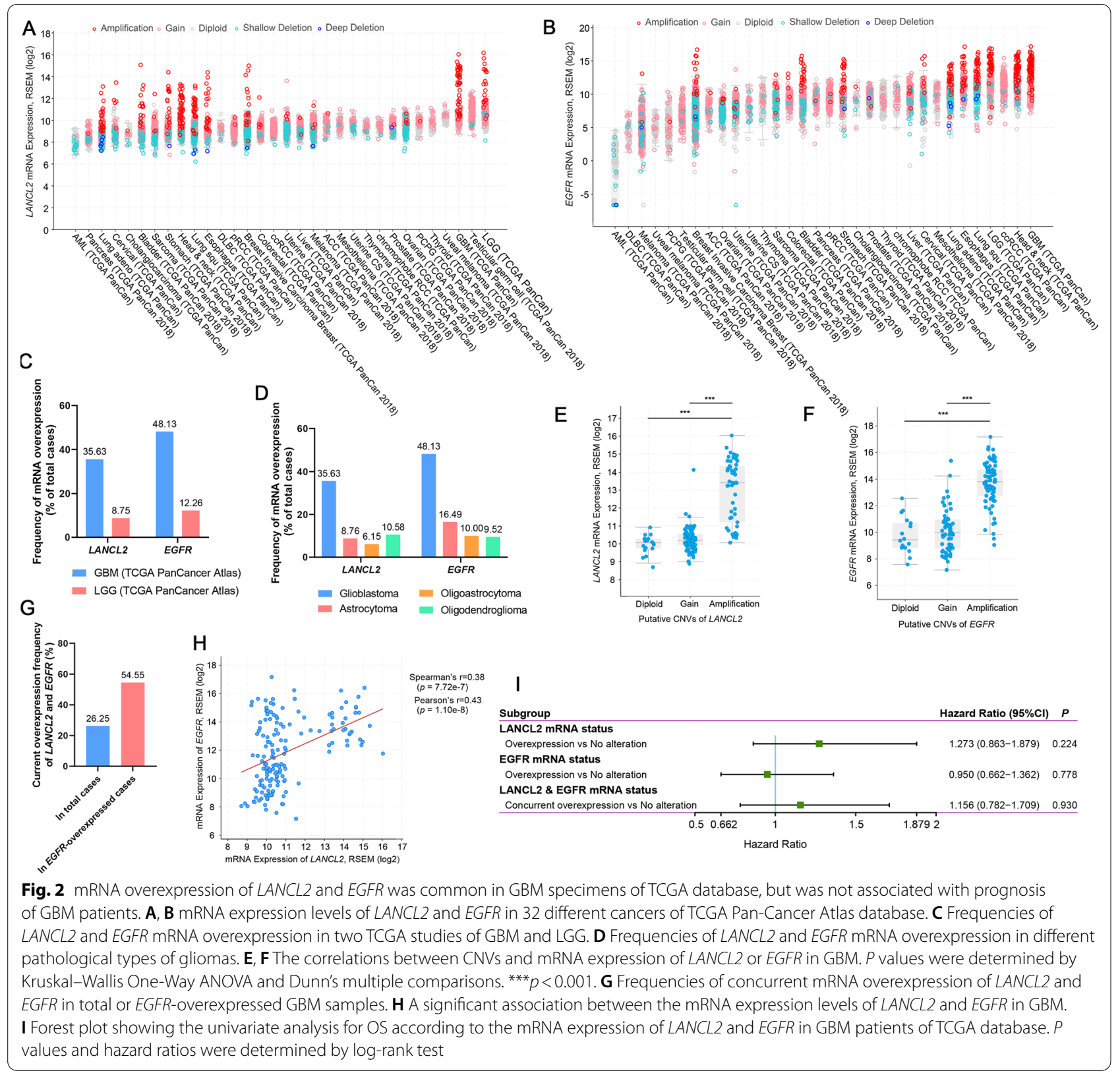

(See figure on next page.)

Fig. 3 Amplification, CO-amplification and their prognostic values of LANCL2 and EGFR were verified in GBM samples of tumor banks. A, B Copy numbers of LANCL2 and EGFR in GBM samples of our tumor banks. Normal brain tissues and grade I gliomas were used for comparison. $P$ values were determined by Kruskal-Wallis One-Way ANOVA and Dunn's multiple comparisons. ${ }^{* *} p<0.001$. C Amplification frequencies of $L A N C L 2$ and EGFR in GBM samples of tumor banks. D Co-amplification frequencies of LANCL2 and EGFR in total or EGFR-amplified GBM samples. E, F Copy numbers of LANCL2 and EGFR in newly diagnosed and relapsing GBM samples. Normal brain tissues and grade I gliomas were used for comparison. $P$ values were determined by Kruskal-Wallis One-Way ANOVA and Dunn's multiple comparisons. ${ }^{*} p<0.05 ;{ }^{* * *} p<0.001$. G Pearson's correlation analysis showed that the copy numbers of LANCL2 and EGFR in GBM were significantly correlated. $\mathbf{H}$ Kaplan-Meier survival analysis of LANCL2 or EGFR amplification, and their co-amplification for OS in GBM patients $\left(^{*} p<0.05\right)$. I Forest plot showing the univariate analysis for OS in GBM patients. $P$ values and hazard ratios were determined by log-rank test. J Kaplan-Meier survival analysis of LANCL2 or EGFR amplification, and their co-amplification for OS in younger ( $<60$ years) GBM patients $\left({ }^{*} p<0.05\right)$ 


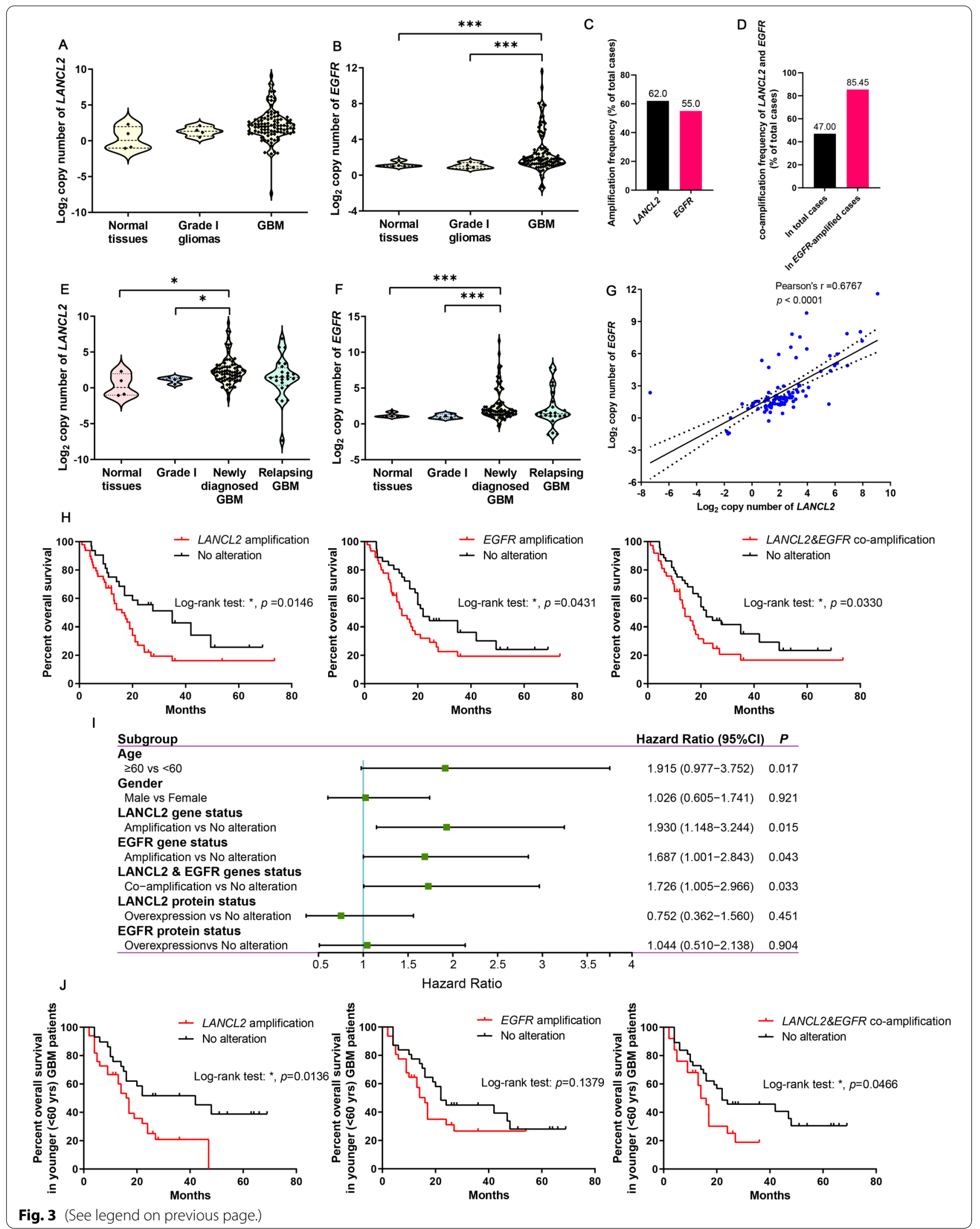


Table 5 Multivariate analysis by the Cox proportional hazard regression model for OS in GBM patients from tumor banks

\begin{tabular}{lll}
\hline Variable & HR $(\mathbf{9 5 \%} \mathrm{Cl})$ & $P$ \\
\hline $\begin{array}{l}\text { Age (years) } \\
\geq 60 \text { vs }<60\end{array}$ & NA & 0.117 \\
$\begin{array}{l}\text { LANCL2 gene status } \\
\text { Amplification vs no alteration }\end{array}$ & $2.319(1.306-4.115)$ & 0.004 \\
$\begin{array}{l}\text { EGFR gene status } \\
\text { Amplification vs no alteration }\end{array}$ & NA & \\
$\begin{array}{l}\text { LANCL2 and EGFR genes status } \\
\text { Co-amplification vs no alteration }\end{array}$ & NA & 0.605 \\
\hline HR hazard ratio, Cl confidence interval, NA not applicable &
\end{tabular}

Table 6 Multivariate analysis by the Cox proportional hazard regression model for OS in younger GBM patients (age $<60$ years) from tumor banks

\begin{tabular}{lll}
\hline Variable & HR $\mathbf{( 9 5 \% ~ C l )}$ & $\boldsymbol{P}$ \\
\hline $\begin{array}{l}\text { Gender } \\
\text { Male vs female }\end{array}$ & NA & 0.791 \\
$\begin{array}{l}\text { LANCL2 gene status } \\
\text { Amplification vs no alteration }\end{array}$ & $2.199(1.142-4.236)$ & 0.018 \\
$\begin{array}{l}\text { EGFR gene status } \\
\text { Amplification vs no alteration }\end{array}$ & NA & 0.805 \\
$\begin{array}{l}\text { LANCL2 and EGFR genes status } \\
\text { Co-amplification vs no alteration }\end{array}$ & NA & \\
\hline
\end{tabular}

$H R$ hazard ratio, $\mathrm{Cl}$ confidence interval, $N A$ not applicable

significantly associated with decreased OS of GBM patients $(\mathrm{n}=81)$, whereas gender was not a significant variable (Fig. $3 \mathrm{H}, \mathrm{I})$. Therefore, gender was excluded as a covariate in the subsequent multivariate analysis, which showed that only LANCL2 amplification was a significant prognostic factor for OS $(p=0.004, \mathrm{HR}=2.319)$ (Table 5). We subsequently divided GBM patients into younger ( $<60 \mathrm{yrs})$ and older ( $\geq 60$ yrs) groups. KaplanMeier survival and multivariate analyses also found that LANCL2 amplification was significantly associated with poor OS $(p=0.018, \mathrm{HR}=2.199)$ in younger GBM patients $(\mathrm{n}=62)$ (Fig. 3J, Table 6). However, gender, LANCL2 and EGFR amplification had no significant influence on OS of older GBM patients $(n=19)$ (Additional file 1: Table S4).

Chi-square tests showed that amplification of LANCL2 was not correlated with IDH1 and TERT mutations, and $M G M T$ methylation, whereas amplification of EGFR was significantly associated with $I D H 1$ and TERT mutations. On the other side, co-amplification of LANCL2 and EGFR was not related with TERT mutation and MGMT methylation, but was correlated with $I D H 1$ mutation (Additional file 1: Figure S3A). Kaplan-Meier survival analysis showed that $L A N C L 2$ or EGFR amplification, and their co-amplification were not correlated with $O S$ in $I D H 1$-wild-type GBM patients $(\mathrm{n}=20)$ (Additional file 1 : Figure S3B).

\section{Protein expression and localization of LanCL2 was independent to EGFR in gliomas}

To investigate the protein expression profiles of LanCL2 and EGFR, 72 GBM samples and 4 low-grade (grade I) glioma samples from our tumor banks were used. Compared with the grade I glioma control, the $\log _{2}$ relative protein expression values larger than 2 was regarded as overexpression. We found that overexpression of LanCL2 and EGFR was found in $38.89 \%$ and $58.33 \%$ of the total GBM samples (Fig. 4A, Additional file 1: Table S6). The protein expression of EGFR was markedly increased in GBM samples, whereas the expression levels of LanCL2 had no significant change (Fig. 4B, C). Interestingly, overexpression of LanCL2 was observed in relapsing GBM compared with newly diagnosed GBM (Fig. 4D, F). On the other hand, although both the newly diagnosed and relapsing GBM samples displayed elevated EGFR expression compared with the grade I glioma samples, no significant change was found between the newly diagnosed and relapsing GBM samples (Fig. 4E, F). Pearson's correlation analysis showed that the expression levels of LanCL2 and EGFR were not correlated (Fig. 4G). Chisquare tests showed that overexpression of LanCL2 or EGFR was not significantly associated with $I D H 1$ or TERT mutations, and MGMT methylation (Fig. 4H). No significant association was also found between the expression of LanCL2/EGFR and OS of GBM patients (Figs. 3I, 4I, J). Subsequently, we used tissue microarray to investigate the expression pattern of LanCL2 and EGFR in GBM cells. Results also showed that the expression scores of both LanCL2 and EGFR were markedly increased in GBM tissues, compared with normal brain tissues (Fig. 5B, D). LanCL2 was expressed in both the normal brain tissues and gliomas. The protein expression level and intracellular localization of LanCL2 were correlated with the grade of gliomas. The higher the glioma grade, the higher the expression intensity of LanCL2. LanCL2 was mainly found in the nucleus and cytoplasm of high-grade glioma cells (grade III-IV), whereas it was expressed on the nuclear membrane of low-grade (grade I-II) glioma cells (Fig. 5A). On the other hand, EGFR was barely expressed in the normal brain tissues and lowgrade gliomas, but was overexpressed in the grade III-IV gliomas. It was mainly located in the plasma membrane and cytoplasm of both low-grade and high-grade glioma cells (Fig. 5C). 


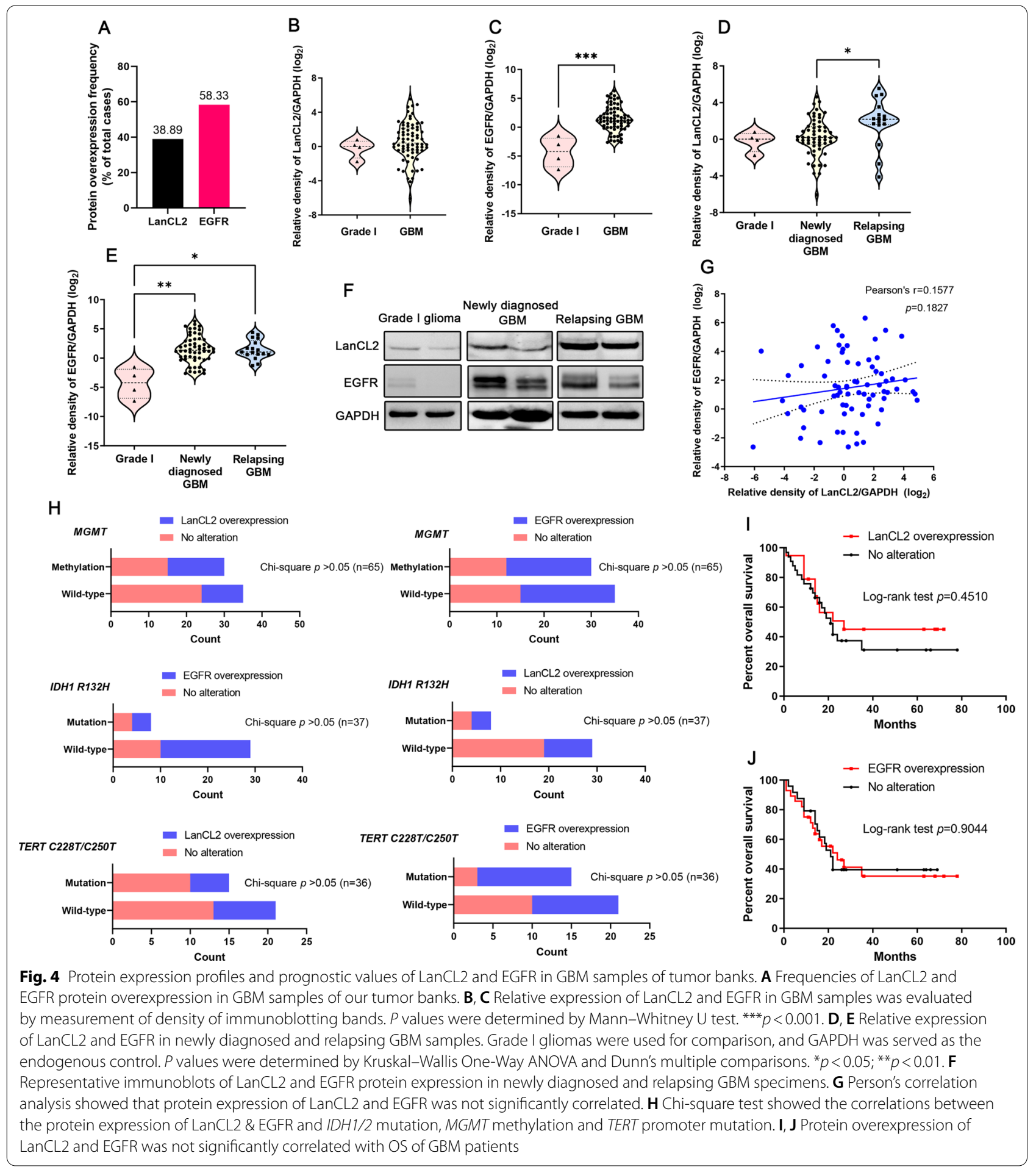

\section{Discussion}

Amplification and overexpression of $E G F R$ are frequently occurred and extensively studied in GBM. Eley et al. found that approximate 34\% (40 of 118 cases) of GBM samples contained EGFR amplification, and 50\% (20 of
40 cases) of EGFR-amplified GBM samples displayed LANCL2 co-amplification [19]. Concomitant amplification or copy number gain of two genes is a common phenomenon in cancers, such as $M Y C N$ and $D D X 1$ in neuroblastoma, ERBB2/HER2 and TOPOIIa in prostate 


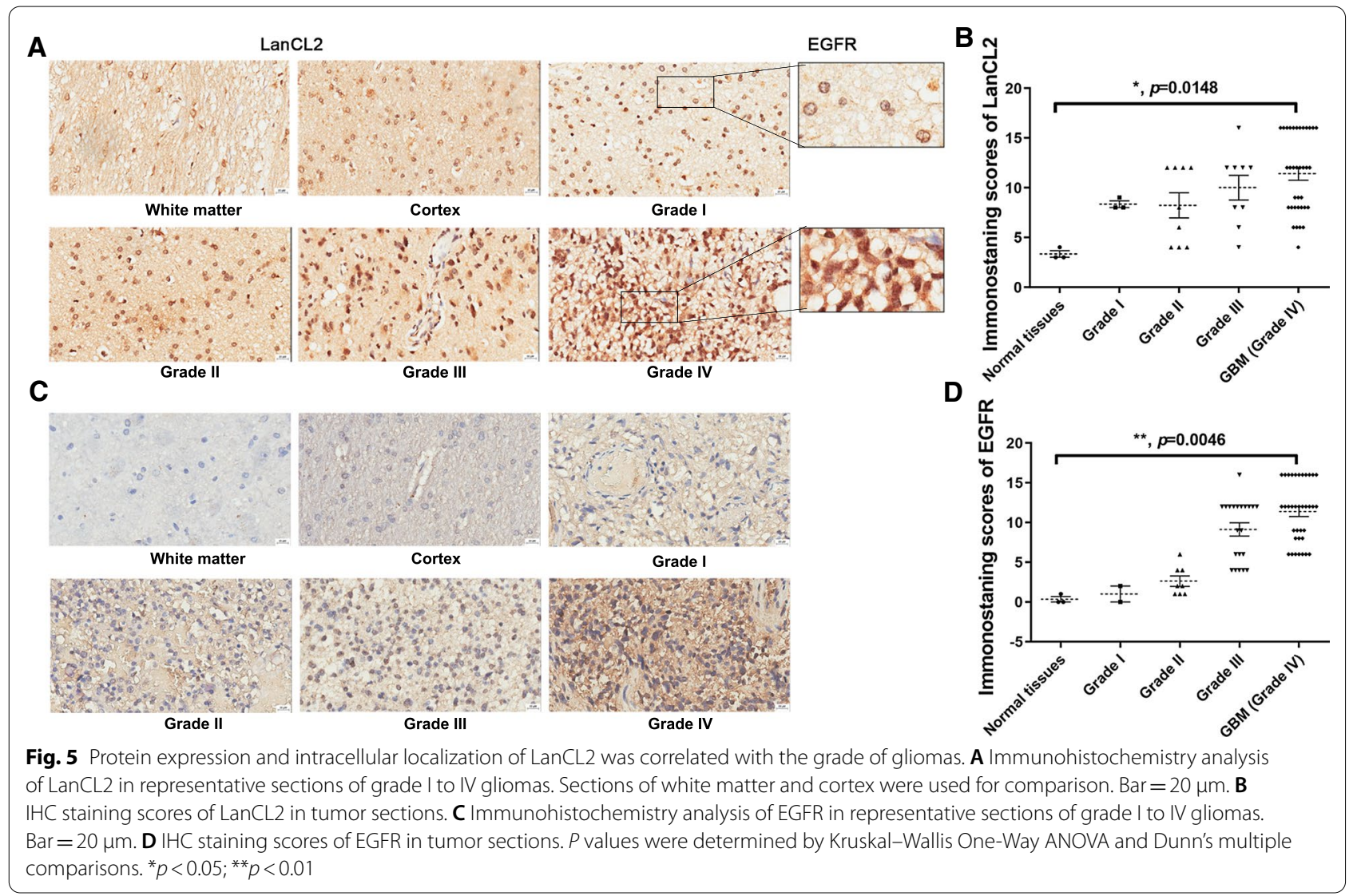

cancer [27-29]. Similar as LANCL2 and EGFR, these genes are located in the same amplification region, which is the driving factor of their co-amplification. Since the co-amplification of LANCL2 and EGFR was found in GBM in 2002, studies of $L A N C L 2$ are barely reported in glioma till now. Only one study using integrative radiogenomic analysis found that the copy number and gene expression of $L A N C L 2$ were significantly increased in multicentric GBM [27]. In this study, we firstly analyzed the TCGA database and found that the amplification frequencies of $L A N C L 2$ and EGFR in GBM were the highest among 32 different types of tumors, indicating the high specificity of $L A N C L 2$ and EGFR amplification in GBM. The frequencies of $L A N C L 2$ and EGFR amplification in 575 GBM patients were approximate $28 \%$ and $44 \%$ respectively, and $62 \%$ of GBM samples with EGFR amplification contained $L A N C L 2$ co-amplification, which were higher than the frequencies reported in Eley's study. In addition, the amplification frequencies of $L A N C L 2$ and $E G F R$ in GBM were six to nine times higher than those in grade II-III gliomas. These findings were verified in 100 GBM samples of our tumor banks, which showed higher amplification and co-amplification frequencies of LANCL2 and EGFR than the results analyzed in TCGA database. Moreover, EGFR is the top gene with the highest amplification frequency in the TCGA database of Glioblastoma Multiforme (PanCancer Atlas) (data not shown). These suggest that amplification of EGFR or coamplification of $L A N C L 2$ and $E G F R$ were potential diagnostic markers for GBM patients.

Univariate analysis of TCGA database and our tumor banks showed that amplification of LANCL2 or EGFR, and their co-amplification were significantly correlated with poor OS, but not PFS of GBM patients. However, since age and gender were significant variables associated with OS in GBM patients of TCGA database, multivariate analysis was performed. No prognostic value of amplification or co-amplification of LANCL2 \& EGFR for OS was shown in multivariate analysis, suggesting that interaction effects among these variables (age, gender, ethnicity, LANCL2 and $E G F R$ genes status) were significant. However, probably due to a smaller sample size of GBM patients, age and gender had no significant impact on the OS of GBM patients from our tumor banks, leading that $L A N C L 2$ amplification was a significant independent prognostic factor for OS in multivariate analysis. In order to eliminate the interference of age, we divided GBM patients into two groups: younger $(<60$ years) and older ( $\geq 60$ years) patients. Multivariate 
analysis of samples from both TCGA database and our tumor banks demonstrated that LANCL2 amplification was a significant independent prognostic factor for OS in younger GBM patients.

Subsequently, we found that $I D H 1 / 2$ mutation, but not $M G M T$ methylation status was correlated with CNVs of LANCL2 and EGFR. However, amplification of LANCL2/ $E G F R$ and their co-amplification were not associated with the OS and PFS of IDH1/2-wild-type GBM patients. Similar studies also find that $E G F R$ amplification is closely associated with wild-type $I D H 1 / 2$ [28]. $C D K N 2 A / B$ deletion, but not TERT mutation or EGFR amplification, was associated with worse OS and PFS of $I D H$-wild-type GBM patients [29]. Our findings indicated that CNVs of $L A N C L 2$ and EGFR were not the independent prognostic factors for $I D H 1 / 2$-wild-type GBM patients.

Numerous studies showed that both the mRNA and protein overexpression of EGFR, which were highly correlated with EGFR amplification, were the signatures and prognostic predictors for GBM patients [30-33]. However, paradox was delineated that the mRNA expression of $E G F R$, not protein expression, showed a close correlation with EGFR amplification [34]. Currently, no study has yet reported the expression profiles and prognostic values of LanCL2 in GBM. In this study, we found that the mRNA expression levels of LANCL2 and EGFR were positively correlated in GBM samples of TCGA database. LANCL2 mRNA expression was significantly increased in LANCL2-amplified samples, so was EGFR. In our tumor banks, we found that the protein expression of EGFR was elevated in GBM samples, whereas LanCL2 expression did not significantly change. The protein expression of LanCL2 and EGFR was not correlated with each other. On the other hand, mRNA and protein overexpression of LanCL2 or EGFR were not associated with OS and PFS in historical GBM patients of TCGA database and our tumor banks, let alone in IDH1/2-wild-type GBM patients. Nevertheless, the roles of LanCL2 and EGFR in GBM cells are of importance and can't be ignored. Plenty of studies showed that EGFR and its active mutant EGFRvIII played critical roles in tumorigenesis, proliferation, angiogenesis, and invasion of GBM [35-38]. However, the role of LanCL2 in GBM remains elusive. In this study, LanCL2 protein overexpression was only found in relapsing GBM compared with newly diagnosed GBM, indicating that LanCL2 overexpression may be correlated with GBM recurrence. In contrast, no significant difference of EGFR expression was found between newly diagnosed and relapsing GBM. Moreover, no significant correlation between LanCL2 and EGFR protein expression was showed. These findings suggest the expression pattern and role of LanCL2 in GBM are independent to EGFR. A study demonstrated that the $\mathrm{N}$-terminus of
LanCL2 protein could be myristoylated and LanCL2 was located in the plasma membrane, juxta-nuclear vesicles, and the nucleus [39]. Here, our immunohistochemical result found that the expression and localization of LanCL2 was correlated with the grade of gliomas. The major localization of LanCL2 in GBM cells was in the nucleus and cytoplasm, whereas it was mainly expressed on the nuclear membrane of LGG cells. Another study showed that LanCL2 is a non-transmembrane G protein-coupled receptor, and its nuclear enrichment was induced by $\mathrm{ABA}$ or its unmyristoylation to activate $\mathrm{ABA}$ signaling [40]. Therefore, we speculated that LanCL2 maintains inactive in the cytoplasm of LGG cells, while LanCL2 transforms to the active form in GBM cells and then translocates into the nucleus.

\section{Conclusion}

In summary, this study showed that amplification and mRNA overexpression of LANCL2 and EGFR, and their co-amplification and co-expression frequently occurred in GBM patients, compared with patients with LGG. Multivariate analysis showed that LANCL2 amplification was significantly correlated with reduced OS in younger ( $<60 \mathrm{yrs}$ ) glioblastoma patients of TCGA database and our tumor banks. LANCL2 or EGFR amplification, and their co-amplification were not associated with OS of older ( $\geq 60$ yrs) or IDH1/2-wild-type GBM patients. In addition, mRNA and protein expression of LanCL2 and EGFR were not correlated with the prognosis of GBM patients. Taken together, amplification of LANCL2 and $E G F R$ were the independent diagnostic biomarkers for glioblastoma patients, and LANCL2 amplification was a significant prognostic factor for OS in younger glioblastoma patients. The protein expression pattern and role of LanCL2 in GBM were independent to EGFR.

\begin{abstract}
Abbreviations
ABA: Abscisic acid; CNV: Copy number variation; EGFR: Epidermal growth factor receptor; GBM: Glioblastoma multiforme; HR: Hazard ratio; IDH: Isocitrate dehydrogenase; IHC: Immunohistochemistry; LANCL2: Lanthionine synthetase C-like 2; LGG: Low-grade glioma; MGMT: O(6)-methylguanine-DNA methyltransferase; OS: Overall survival; PFS: Progression-free survival; RTK: Receptor tyrosine kinase; TASP: Testis adriamycin sensitivity protein; TERT:Telomerase reverse transcriptase; TCGA: The Cancer Genome Atlas; WHO: World Health Organization.
\end{abstract}

\section{Supplementary Information}

The online version contains supplementary material available at https://doi. org/10.1186/s12967-021-02979-z.

Additional file 1: Figure S1. Prognostic values of $\angle A N C L 2$ and $E G F R$ amplification for OS and PFS in GBM patients of TCGA database. Figure S2. mRNA overexpression of LANCL2 and EGFR was not associated with prognosis of historical or IDH1/2-wild-type GBM patients. Figure S3. The prognostic values of amplification of $\angle A N C L 2$ or EGFR, and their 
co-amplification in IDH1/2-wild-type GBM patients from Shenzhen Second People's Hospital and Sun Yat-sen University Cancer Center. Table S1. Multivariate analysis by the Cox proportional hazard regression model in a forward manner in older GBM patients (age $\geq 60 \mathrm{yrs}$ ) of TCGA database. Table S2. Univariate analysis for OS and PFS in IDH1/2-wild-type GBM patients of TCGA database. Table S3. Multivariate analysis by the Cox proportional hazard regression model for OS in IDH1/2-wild-type GBM patients of TCGA database. Table S4. Multivariate analysis by the Cox proportional hazard regression model in a forward manner in older GBM patients (age $\geq 60 \mathrm{yrs}$ ) from tumor banks. Table S5. Amplification and co-amplification of LANCL2 and EGFR in GBM samples of tumor banks. Table S6. Protein overexpression of LanCL2 and EGFR in GBM samples of tumor banks.

\section{Acknowledgements}

The authors would like to thank the support of Shenzhen Key Laboratory of Neurosurgery and the Shenzhen Research and Clinical Translational Platform of Brain Tumor Precision Medicine Key Technology.

\section{Authors' contributions}

$\mathrm{HZ}$ analyzed and interpreted all the data, performed the in-vitro experiments, was the major contributor in writing the manuscript. XZ performed the follow-up study and collected the clinical information of patients. JW, FC and LC provided the patients' samples and clinical information. CW, PD and LC carried out parts of the in-vitro experiments including copy number assay and immunohistochemistry. XW and JL performed the pathologic analysis. ZL, WL and ZC provided suggestions to the study. GH and WL provided guidance of the statistical analysis and revised the manuscript. All authors read and approved the final manuscript.

\section{Funding}

This work was supported by grants from National Natural Science Foundation of China (No. 81602195, 81772685), Natural Science Foundation of Guangdong Province (No. 2021A1515012143, No. 2017A030313531), Shenzhen Science and Technology Innovation Commission (No. JCYJ20160425104157183), Open Funds of State Key Laboratory of Oncology in South China (No. HN201811), and Shenzhen Double Chain Grant (No. [2018] 256).

\section{Availability of data and materials}

The datasets analyzed during the current study are available in the TCGA repository, http://www.cbioportal.org.

\section{Declarations}

\section{Ethics approval and consent to participate}

This study was approved by the Research Ethics Committee of Shenzhen Second People's Hospital and Sun Yat-sen University Cancer Center. All patients were given written informed consent. The use of human tissues in tissue microarray slides was approved by the Ethics Committee of Shanghai Outdo Biotech Company.

\section{Consent for publication}

This study has been approved by all authors for publication.

\section{Competing interests}

The authors declare that they have no competing interests.

\section{Author details}

'Department of Neurosurgery, Institute of Translational Medicine, The First Affiliated Hospital of Shenzhen University, Shenzhen Second People's Hospital, Shenzhen 518035, China. ${ }^{2}$ Epilepsy Center, Guangdong 999 Brain Hospital, Guangzhou 510510, China. ${ }^{3}$ Department of Neurosurgery/Neuro-Oncology, Sun Yat-Sen University Cancer Center, Guangzhou 510060, China. ${ }^{4}$ State Key Laboratory of Oncology in South China, Guangzhou 510060, China. ${ }^{5}$ Collaborative Innovation Center for Cancer Medicine, Guangzhou 510060, China. ${ }^{6}$ Department of Neurosurgery, People's Hospital of Longhua District, Shenzhen 518109, China. ${ }^{7}$ Department of Pathology, The First Affiliated Hospital of Shenzhen University, Shenzhen Second People's Hospital, Shenzhen 518035, China.
Received: 24 February 2021 Accepted: 6 July 2021

Published online: 30 August 2021

\section{References}

1. Dolecek TA, Propp JM, Stroup NE, Kruchko C. CBTRUS statistical report: primary brain and central nervous system tumors diagnosed in the United States in 2005-2009. Neuro Oncol. 2012;14(Suppl 5):1-49.

2. Ostrom QT, Gittleman H, Truitt G, Boscia A, Kruchko C, Barnholtz-Sloan JS. CBTRUS statistical report: primary brain and other central nervous system tumors diagnosed in the United States in 2011-2015. Neuro Oncol. 2018;20(suppl_4):iv1-86.

3. Schwartzbaum JA, Fisher JL, Aldape KD, Wrensch M. Epidemiology and molecular pathology of glioma. Nat Clin Pract Neurol. 2006;2(9):494-503.

4. Stupp R, Mason WP, van den Bent MJ, Weller M, Fisher B, Taphoorn MJ, et al. Radiotherapy plus concomitant and adjuvant temozolomide for glioblastoma. N Engl J Med. 2005;352(10):987-96.

5. Yan H, Parsons DW, Jin G, McLendon R, Rasheed BA, Yuan W, et al. IDH1 and IDH2 mutations in gliomas. N Engl J Med. 2009;360(8):765-73.

6. Simon M, Hosen I, Gousias K, Rachakonda S, Heidenreich B, Gessi M, et al. TERT promoter mutations: a novel independent prognostic factor in primary glioblastomas. Neuro Oncol. 2015;17(1):45-52.

7. Brennan CW, Verhaak RG, McKenna A, Campos B, Noushmehr H, Salama SR, et al. The somatic genomic landscape of glioblastoma. Cell. 2013;155(2):462-77.

8. Ohgaki H, Kleihues P. Population-based studies on incidence, survival rates, and genetic alterations in astrocytic and oligodendroglial gliomas. J Neuropathol Exp Neurol. 2005;64(6):479-89.

9. Ohgaki H, Kleihues P. Genetic pathways to primary and secondary glioblastoma. Am J Pathol. 2007;170(5):1445-53.

10. Shinojima N, Tada K, Shiraishi S, Kamiryo T, Kochi M, Nakamura H, et al. Prognostic value of epidermal growth factor receptor in patients with glioblastoma multiforme. Cancer Res. 2003;63(20):6962-70.

11. Simmons ML, Lamborn KR, Takahashi M, Chen P, Israel MA, Berger MS, et al. Analysis of complex relationships between age, p53, epidermal growth factor receptor, and survival in glioblastoma patients. Cancer Res. 2001;61(3):1122-8.

12. Bienkowski M, Piaskowski S, Stoczynska-Fidelus E, Szybka M, Banaszczyk M, Witusik-Perkowska M, et al. Screening for EGFR amplifications with a novel method and their significance for the outcome of glioblastoma patients. PLoS ONE. 2013;8(6): e65444.

13. Chen JR, $X u H Z$, Yao Y, Qin ZY. Prognostic value of epidermal growth factor receptor amplification and EGFRvIII in glioblastoma: meta-analysis. Acta Neurol Scand. 2015;132(5):310-22.

14. Mayer H, Pongratz M, Prohaska R. Molecular cloning, characterization, and tissue-specific expression of human LANCL2, a novel member of the LanC-like protein family. DNA Seq. 2001;12(3):161-6.

15. Sturla L, Fresia C, Guida L, Bruzzone S, Scarfi S, Usai C, et al. LANCL2 is necessary for abscisic acid binding and signaling in human granulocytes and in rat insulinoma cells. J Biol Chem. 2009;284(41):28045-57.

16. Park $S$, James CD. Lanthionine synthetase components C-like 2 increases cellular sensitivity to adriamycin by decreasing the expression of P-glycoprotein through a transcription-mediated mechanism. Cancer Res. 2003;63(3):723-7.

17. Bassaganya-Riera J, Guri AJ, Lu P, Climent M, Carbo A, Sobral BW, et al. Abscisic acid regulates inflammation via ligand-binding domain-independent activation of peroxisome proliferator-activated receptor gamma. J Biol Chem. 2011;286(4):2504-16.

18. Leber A, Hontecillas R, Zoccoli-Rodriguez V, Bassaganya-Riera J. Activation of LANCL2 by BT-11 ameliorates IBD by supporting regulatory T cell stability through immunometabolic mechanisms. Inflamm Bowel Dis. 2018. https://doi.org/10.1093/ibd/izy167.

19. Eley GD, Reiter JL, Pandita A, Park S, Jenkins RB, Maihle NJ, et al. A chromosomal region 7p11.2 transcript map: its development and application to the study of EGFR amplicons in glioblastoma. Neuro Oncol. 2002;4(2):86-94.

20. Lu Z, Zhou L, Killela P, Rasheed AB, Di C, Poe WE, et al. Glioblastoma protooncogene SEC61gamma is required for tumor cell survival and response to endoplasmic reticulum stress. Cancer Res. 2009;69(23):9105-11. 
21. Cerami E, Gao J, Dogrusoz U, Gross BE, Sumer SO, Aksoy BA, et al. The cBio cancer genomics portal: an open platform for exploring multidimensional cancer genomics data. Cancer Discov. 2012;2(5):401-4

22. Gao J, Aksoy BA, Dogrusoz U, Dresdner G, Gross B, Sumer SO, et al. Integrative analysis of complex cancer genomics and clinical profiles using the cBioPortal. Sci Signal. 2013;6(269):pl1.

23. Liu J, Lichtenberg T, Hoadley KA, Poisson LM, Lazar AJ, Cherniack AD, et al. An integrated TCGA pan-cancer clinical data resource to drive highquality survival outcome analytics. Cell. 2018;173(2):400-16 e11.

24. Hoadley KA, Yau C, Hinoue T, Wolf DM, Lazar AJ, Drill E, et al. Cell-of-origin patterns dominate the molecular classification of 10,000 tumors from 33 types of cancer. Cell. 2018;173(2):291-304 e6.

25. Ding L, Bailey MH, Porta-Pardo E, Thorsson V, Colaprico A, Bertrand D, et al. Perspective on oncogenic processes at the end of the beginning of cancer genomics. Cell. 2018;173(2):305-20 e10.

26. Sanchez-Vega F, Mina M, Armenia J, Chatila WK, Luna A, La KC, et al. Oncogenic signaling pathways in the cancer genome atlas. Cell. 2018;173(2):321-37 e10

27. Kong DS, Kim J, Lee IH, Kim ST, Seol HJ, Lee Jl, et al. Integrative radiogenomic analysis for multicentric radiophenotype in glioblastoma. Oncotarget. 2016;7(10):11526-38.

28. Stichel D, Ebrahimi A, Reuss D, Schrimpf D, Ono T, Shirahata M, et al. Distribution of EGFR amplification, combined chromosome 7 gain and chromosome 10 loss, and TERT promoter mutation in brain tumors and their potential for the reclassification of IDHwt astrocytoma to glioblastoma. Acta Neuropathol. 2018;136(5):793-803.

29. Ma S, Rudra S, Campian JL, Dahiya S, Dunn GP, Johanns T, et al. Prognostic impact of CDKN2A/B deletion, TERT mutation, and EGFR amplification on histological and molecular IDH-wildtype glioblastoma. Neurooncol Adv. 2020;2(1):vdaa126.

30. Hodgson JG, Yeh RF, Ray A, Wang NJ, Smirnov I, Yu M, et al. Comparative analyses of gene copy number and mRNA expression in glioblastoma multiforme tumors and xenografts. Neuro Oncol. 2009;11(5):477-87.

31. Viana-Pereira M, Lopes JM, Little S, Milanezi F, Basto D, Pardal F, et al. Analysis of EGFR overexpression, EGFR gene amplification and the EGFRvIII mutation in Portuguese high-grade gliomas. Anticancer Res. 2008;28(2A):913-20.
32. Li J, Liang R, Song C, Xiang Y, Liu Y. Prognostic significance of epidermal growth factor receptor expression in glioma patients. Onco Targets Ther. 2018;11:731-42.

33. Lopez-Gines C, Gil-Benso R, Ferrer-Luna R, Benito R, Serna E, GonzalezDarder J, et al. New pattern of EGFR amplification in glioblastoma and the relationship of gene copy number with gene expression profile. Mod Pathol. 2010;23(6):856-65.

34. Lassman AB, Roberts-Rapp L, Sokolova I, Song M, Pestova E, Kular R, et al. Comparison of biomarker assays for EGFR: implications for precision medicine in patients with glioblastoma. Clin Cancer Res. 2019;25(11):3259-65.

35. Katanasaka Y, Kodera Y, Kitamura Y, Morimoto T, Tamura T, Koizumi F. Epidermal growth factor receptor variant type III markedly accelerates angiogenesis and tumor growth via inducing c-myc mediated angiopoietin-like 4 expression in malignant glioma. Mol Cancer. 2013;12:31.

36. An Z, Aksoy O, Zheng T, Fan QW, Weiss WA. Epidermal growth factor receptor and EGFRvIII in glioblastoma: signaling pathways and targeted therapies. Oncogene. 2018;37(12):1561-75.

37. Eskilsson E, Rosland GV, Solecki G, Wang Q, Harter PN, Graziani G, et al. EGFR heterogeneity and implications for therapeutic intervention in glioblastoma. Neuro Oncol. 2018;20(6):743-52.

38. Talasila KM, Soentgerath A, Euskirchen P, Rosland GV, Wang J, Huszthy PC, et al. EGFR wild-type amplification and activation promote invasion and development of glioblastoma independent of angiogenesis. Acta Neuropathol. 2013;125(5):683-98.

39. Landlinger C, Salzer U, Prohaska R. Myristoylation of human LanC-like protein 2 (LANCL2) is essential for the interaction with the plasma membrane and the increase in cellular sensitivity to adriamycin. Biochim Biophys Acta. 2006;1758(11):1759-67.

40. Fresia C, Vigliarolo T, Guida L, Booz V, Bruzzone S, Sturla L, et al. G-protein coupling and nuclear translocation of the human abscisic acid receptor LANCL2. Sci Rep. 2016;6:26658.

\section{Publisher's Note}

Springer Nature remains neutral with regard to jurisdictional claims in published maps and institutional affiliations.
Ready to submit your research? Choose BMC and benefit from:

- fast, convenient online submission

- thorough peer review by experienced researchers in your field

- rapid publication on acceptance

- support for research data, including large and complex data types

- gold Open Access which fosters wider collaboration and increased citations

- maximum visibility for your research: over $100 \mathrm{M}$ website views per year

At BMC, research is always in progress.

Learn more biomedcentral.com/submissions 